\title{
Influence of Front and Back Contacts on Photovoltaic Performances of p-n Homojunction Si Solar Cell: Considering an Electron-Blocking Layer
}

\author{
Md. Feroz Ali ${ }^{1}$ and Md. Faruk Hossain ${ }^{2}$ \\ ${ }^{1}$ Department of Electrical and Electronic Engineering (EEE), Pabna University of Science \& Technology (PUST), \\ Pabna 6600, Bangladesh \\ ${ }^{2}$ Electrical \& Electronic Engineering, Rajshahi University of Engineering \& Technology (RUET), Rajshahi 6204, Bangladesh \\ Correspondence should be addressed to Md. Feroz Ali; feroz071021@gmail.com
}

Received 17 November 2016; Accepted 22 January 2017; Published 12 March 2017

Academic Editor: Yatendra S. Chaudhary

Copyright @ 2017 Md. Feroz Ali and Md. Faruk Hossain. This is an open access article distributed under the Creative Commons Attribution License, which permits unrestricted use, distribution, and reproduction in any medium, provided the original work is properly cited.

\begin{abstract}
In this simultion work, the effect of front and back contacts of p-n homojunction Si solar cell with an electron-blocking layer (EBL) has been studied with the help of a strong solar cell simulator named AMPS-1D (analysis of microelectronic and photonic structures one dimensional). Without the effect of these contact parameters, low solar cell efficiency has been observed. Fluorine-doped tin oxide (FTO) with high work function $(5.45 \mathrm{eV})$ has been used as the front contact to the proposed solar cell. Zinc ( $\mathrm{Zn})$ metal which has a work function of $4.3 \mathrm{eV}$ has been used as the back contact of the proposed model. With FTO as the front contact and Zn as the back contact, the optimum efficiency of $29.275 \%$ $\left(\mathrm{Voc}=1.363 \mathrm{~V}, \mathrm{Jsc}=23.747 \mathrm{~mA} / \mathrm{cm}^{2}, \mathrm{FF}=0.905\right)$ has been observed. This type of simple Si-based $\mathrm{p}$-n homojunction solar cell with EBL of high efficiency has been proposed in this paper.
\end{abstract}

\section{Introduction}

Because of the increasing trend of price of fossil fuels and some of their drastic and dangerous effects on greenhouse, the world is now looking for green energy like solar cells [1]. For its green power, low cost, and availability, renewable energy plays an important role in the world energy, especially solar photovoltaic cell which has a great contribution to the world's electrical energy. Solar energy [2] is another increasingly hot topic in recent years due to the inevitable exhaustion of fossil and mineral energy sources in the next fifty years [3]. Although solar cell has a great disadvantage of higher initial cost, after payback, it is still the best option for clean energy. For example, the calculated energy payback for the current PV systems is 3-4 years, which depends on the type of PV panel (thin film technology or multicrystalline silicon), but this time may be expected to be reduced to 1-2 years as manufacturing techniques improve [4]. People all over the world have investigated different types of silicon solar cells for many years [5]. One of the main reasons that silicon is the choice for semiconductor material in the field of microelectronics is that it forms a unique oxide on the surface when heated to high temperatures which facilitates device fabrication for two reasons: (i) it neutralizes defects on the silicon surface and (ii) it allows for straightforward planar processing [6]. The performance of solar photovoltaic cells depends on their design, material properties, and fabrication technology; that is why researchers present improved cells over periods of time, although the overall process is not only quite complex but also expensive and time-consuming [7]. One of the best methods for simulating solar cell is the numerical approach which helps the researchers to find out a design optimization. There are many major objectives of numerical modeling and simulation in solar cell research such as testing the validity of the proposed physical structures and geometry on solar cell performance and fitting the modeling output 
to experimental results, which have become indispensable tools for designing a high-efficiency solar cell [7]. The front and back contacts have great influence on efficiency as well as performance of silicon solar cell. Ni back contact gives high performance compared with other metals [8]. The efficiency of solar cell also depends on the work function [9] of the front and back contacts. The work function, $\Phi$, is the energy required to remove an electron from the highest filled level in the stationary Fermi distribution of a solid, a point in a field-free zone just outside the solid, at absolute zero. The relatively high evaporation rates can be achieved with low work function materials and must be operated at lower temperatures [10]. Highperformance electrodes must exhibit a low work function, $\varphi$, uniformly over the electrode surface. The electron source community has identified several promising materials that can uniformly reduce $\varphi$ through the use of surface adsorbents and/or bandgap modification [10]. The theoretical efficiency limits of solar energy conversion are strongly dependent not only on the range but also on a number of different bandgaps or effective bandgaps that can be incorporated into a solar cell [11].

In this work, $\mathrm{p}-\mathrm{n}$ homojunction $\mathrm{Si}$ solar cell with an electron-blocking layer (EBL) [1] has been studied with the variation of front and back contact parameters such as the work function $(\mathrm{eV})$ and reflection coefficient. For the simulation of this device, a strong solar cell simulator named AMPS-1D (analysis of microelectronic and photonic structures one dimensional) has been used. Other parameters/data of the solar cell device have been adopted from various practical references [12]. Although some have carried out this topic before [1], this study is the first and unique one to consider the work function and reflection coefficient of the front and back contacts to improve the efficiency of $\mathrm{Si}$ homojunction solar cell. Authors have been tried to simulate this solar cell, and the efficiency of $29.275 \%$ has been observed at the thickness of $6000 \mathrm{~nm}$ for each p-layer $\mathrm{Si}$ and n-layer $\mathrm{Si}$ and $50 \mathrm{~nm}$ of EBL with $2.10 \mathrm{eV}$ bandgap along with the work functions of the front and back contacts which are $1.5 \mathrm{eV}$ and $0.5 \mathrm{eV}$, respectively.

\section{Simulation Model}

In AMPS software, the physics of device transport can be captured in three governing equations: Poisson's equation, the continuity equation for free holes, and the continuity equation for free electrons [13]. Determining transport characteristics then becomes a task of solving these three coupled nonlinear differential equations subject to appropriate boundary conditions. These three equations and the corresponding boundary conditions, along with the numerical solution technique used to solve them. AMPS software assumes that the material system under examination is in steady state. That is, it is assumed that there is no time dependence. It follows that the terminal characteristics generated by AMPS are the quasi-static characteristics. Table 1 shows the boundary conditions of the front and back contacts of AMPS. PHIBO is the difference
TABLE 1: Boundary conditions of the front and back contacts of AMPS.

\begin{tabular}{lc}
\hline Contact parameters & Description \\
\hline PHIBO $=\Phi_{\mathrm{bo}}($ front contact $)$ & $E_{\mathrm{c}}-E_{\mathrm{f}}$ in at $x=0(\mathrm{eV})$ \\
$\mathrm{PHIBL}=\Phi_{\mathrm{bL}}($ back contact $)$ & $\mathrm{E}_{\mathrm{c}}-E_{\mathrm{f}}$ in at $x=L(\mathrm{eV})$ \\
\hline
\end{tabular}

between the work function of the front contact and electron affinity of the semiconductor in contact. Similarly, PHIBL is the difference between the work function of the back contact and electron affinity of the semiconductor in contact.

PHIBO is the difference between the work function of the front contact and the electron affinity of the associated semiconductor. Similarly, the PHIBL is the difference between the work function of the back contact and the electron affinity of the associated semiconductor. Table 2 shows the surface recombination speed of AMPS. Here, for the simulation, the SNO, SPO, SNL, and SPL were all selected as $1 \mathrm{e} 7 \mathrm{~cm} / \mathrm{sec}$.

Table 3 shows the reflection coefficient for light impinging on the front and back surfaces. In this case, RF 0.1 and RB 0.9 have been selected for the simulation. It means that the front contact of the device can reflect only $10 \%$ of the incident light and the back contact of the device can reflect $90 \%$ of the incident light.

\section{The Proposed Model with Front and Back Contact Parameters}

Figure 1 shows the $\mathrm{p}-\mathrm{n}$ homojunction solar cell with EBL and the front and back contact parameters. The spectral response (SR) has been observed with this model.

In the proposed device, $\mathrm{p}$-n solar cell with p-type $\mathrm{Si}$ of $6000 \mathrm{~nm}$ in thickness and also with n-type Si solar cell of $6000 \mathrm{~nm}$ in thickness has been incorporated along with the proper front and back contacts in order to enhance efficiency. As some researches have been carried out on this homojunction Si solar cell, this is the first research with AMPS to consider the proper front and back contacts. A $50 \mathrm{~nm}$ thick electron-blocking layer (EBL) has been embodied on the top of the $\mathrm{p}-\mathrm{n}$ diode where light is immersed. It has been observed that the higher the thickness of $\mathrm{p}-\mathrm{n}$ Si layer, the higher the efficiency. But with p-n Si layer of $6000 \mathrm{~nm}$ thickness, the optimum efficiency is $29.275 \%$, comparatively higher than conventional Si solar cell. For this solar cell simulation, a PHIBO (work function of the front contact) of $1.6 \mathrm{eV}$ and reflection coefficient of 0.1 and a PHIBL (work function of the back contact) of $0.5 \mathrm{eV}$ and reflection coefficient of 0.9 have been selected. The simulation result shows that the efficiency and performance of the solar cell device are optimum; hence, these are the best solar cell contacts with the corresponding parameters for this device.

\section{Simulation Parameters}

The parameters included in Table 4 and Table 5 are used to simulate the solar cell in AMPS-1D. The temperature of $300 \mathrm{~K}$ is used as the default, and to get the all results, 
TABLE 2: Surface recombination speed of AMPS.

\begin{tabular}{lc}
\hline Contact parameters & Description \\
\hline SNO (recombination speed of the electron of the front contact) & Electrons at $x=0$ interface $(\mathrm{cm} / \mathrm{sec})$ \\
SPO (recombination speed of the hole of the front contact) & Hole at $x=0$ interface $(\mathrm{cm} / \mathrm{sec})$ \\
SNL (recombination speed of the electron of the back contact) & Electrons at $x=L$ interface $(\mathrm{cm} / \mathrm{sec})$ \\
SPL (recombination speed of the hole of the front contact) & Hole at $x=L$ interface $(\mathrm{cm} / \mathrm{sec})$ \\
\hline
\end{tabular}

TABLE 3: Reflection coefficient for light impinging on the front and back surfaces.

\begin{tabular}{ll}
\hline Contact parameters & \multicolumn{1}{c}{ Description } \\
\hline $\mathrm{RF}$ & Reflection coefficient at $x=0$ (front surface) \\
$\mathrm{RB}$ & Reflection coefficient at $x=L$ (back surface) \\
\hline
\end{tabular}

AM 1.5 illuminations are used. AM means air mass coefficient. The air mass coefficient is defined as the direct optical path length through the Earth's atmosphere, expressed as the ratio relative to the path length vertically upwards, that is, at the zenith [14].

\section{Simulation Result and Discussion}

Figure 2 shows the PHIBO versus efficiency plot of the proposed solar cell's front contact. We have tried to simulate the front contact PHIBO from $1.2 \mathrm{eV}$ to $2.2 \mathrm{eV}$. It has been observed that, at $1.6 \mathrm{eV}$ PHIBO, the efficiency is $29.275 \%$. Before the value of $1.6 \mathrm{eV}$, which has a drastic effect on efficiency, and beyond the value of $1.6 \mathrm{eV}$, the efficiency has a negligible increase. That is why the PHIBO is $1.6 \mathrm{eV}$ which is the optimum value of the proposed solar cell. Figure 3 shows the PHIBO versus Voc plot of the proposed solar cell's front contact. It has been observed that, at PHIBO $1.6 \mathrm{eV}$, the open circuit voltage is $1.363 \mathrm{~V}$ and it is the optimum value as Figure 3 describes. Figure 4 shows the PHIBO versus Jsc plot of the proposed solar cell's front contact. The plot describes that the short circuit current of the solar cell increases with the increase in PHIBO but the changes are quite small. Figure 5 shows the PHIBO versus fill factor plot of the proposed solar cell's front contact. It has been observed that the fill factor is optimum (0.905) at PHIBO $1.6 \mathrm{eV}$.

Figure 6 shows the PHIBL versus efficiency plot of the proposed solar cell's back contact. We have tried to vary the PHIBL from $0.1 \mathrm{eV}$ to $0.8 \mathrm{eV}$. It has been observed that the optimum efficiency $(29.275 \%)$ has been achieved at PHIBL $0.5 \mathrm{eV}$. After $0.5 \mathrm{eV}$, the efficiency has been drastically affected as shown in the plot. Figure 7 shows the PHIBL versus Jsc plot of the proposed solar cell's back contact. Here, the short circuit current has no effect (almost the same, i.e., $23.747 \mathrm{~mA} / \mathrm{cm}^{2}$ ) on PHIBL as shown in the plot. Figure 8 shows the PHIBL versus fill factor (FF) plot of the proposed solar cell's back contact. The optimum FF (0.905) has been observed at PHIBL $0.5 \mathrm{eV}$. FF has been decreasing sharply after PHIBL $0.5 \mathrm{eV}$ which is depicted in Figure 8. Figure 9

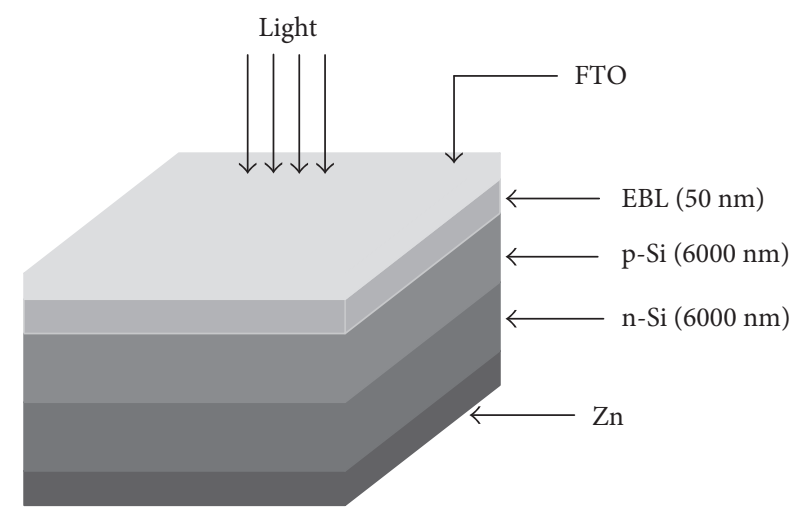

Figure 1: The proposed schematic diagram of $\mathrm{p}-\mathrm{n}$ homojunction solar cell with EBL.

shows the PHIBL versus Voc plot of the proposed solar cell's back contact. The optimum open circuit voltage $(1.363 \mathrm{~V})$ has been observed at PHIBL $0.5 \mathrm{eV}$ as shown in the graph.

Figure 10 shows the $J-V$ and $P-V$ plots of the proposed solar cell. Here, the maximum power of $29.28434 \mathrm{~mW} / \mathrm{cm}^{2}$ has been observed.

Figure 11 shows the band diagram of the proposed solar cell. This figure shows the difference between the conduction and valence band as well as the difference between the Fermi labels of the proposed solar cell's front and back contacts.

\section{Conclusion}

To conclude, for the front contact of the solar cell, a PHIBO of $1.6 \mathrm{eV}$, SNO and SPO of $1.0 \times 10^{7} \mathrm{~cm} / \mathrm{sec}$, and reflection coefficient (RF) of $0.1(10 \%)$ have been observed as the optimum values which correspond to FTO with high work function $(5.45 \mathrm{eV})$. Also, for the back contact of the solar cell, a PHIBL of $0.6 \mathrm{eV}$, SNL and SPL of $1.0 \times 10^{7} \mathrm{~cm} / \mathrm{sec}$, and reflection coefficient (RB) of 0.9 (90\%) have been observed as the optimum values which correspond to metal $\mathrm{Zn}(4.3 \mathrm{eV})$. With these front and back contact parameters, the solar cell has the following performance parameters: Voc $1.363 \mathrm{~V}$, Jsc $23.747 \mathrm{~mA} / \mathrm{cm}^{2}$, FF 0.905 , efficiency $29.275 \%$, and maximum power $29.28434 \mathrm{~mW} / \mathrm{cm}^{2}$. By controlling the bandgap and band state parameters, the efficiency can also be improved. So, this kind of p-n homojunction Si solar cell with the following proposed front contact (FTO) and back contact (Zn) can be fabricated in the laboratory and can be compared with the simulation result in the future. 
TABLE 4: Different layers of electronic properties used in the APMS simulation.

\begin{tabular}{lccc}
\hline Electronic properties & EBL & $\mathrm{p}-\mathrm{Si}$ & $\mathrm{n}$-Si \\
\hline Relative permittivity, $\varepsilon_{\mathrm{r}}$ & 11.9 & 20.0 & 11.9 \\
Electron mobility, $\mu_{\mathrm{n}}\left(\mathrm{cm}^{2} / \mathrm{v}\right.$-s $)$ & 40.0 & 2.0 & 20.0 \\
Hole mobility, $\mu_{\mathrm{p}}\left(\mathrm{cm}^{2} / \mathrm{v}\right.$-s) & 4.0 & $N_{\mathrm{A}}=1.0 \times 10^{18}$ & 2.0 \\
Acceptor \& donor concentration $\left(\mathrm{cm}^{-3}\right)$ & $N_{\mathrm{A}}=1.0 \times 10^{18}$ & 1.82 & $N_{\mathrm{D}}=1.0 \times 10^{18}$ \\
Bandgap $(\mathrm{eV})$ & 2.10 & $2.5 \times 10^{20}$ & 1.82 \\
Effective density of states in the conduction band $\left(\mathrm{cm}^{-3}\right)$ & $2.5 \times 10^{20}$ & $2.5 \times 10^{20}$ & $2.5 \times 10^{20}$ \\
Effective density of states in the valence band $\left(\mathrm{cm}^{-3}\right)$ & $2.5 \times 10^{20}$ & 3.80 & $2.5 \times 10^{20}$ \\
Electron affinity $(\mathrm{eV})$ & 3.85 & 3.80 \\
\hline
\end{tabular}

TABLE 5: Optimum values of the front and back contact parameters.

\begin{tabular}{lc}
\hline Front contact & Back contact \\
\hline $\mathrm{PHIBO}=1.60 \mathrm{eV}$ & $\mathrm{PHIBL}=0.50 \mathrm{eV}$ \\
$\mathrm{SNO}=1.0 \times 10^{7} \mathrm{~cm} / \mathrm{sec}$ & $\mathrm{SNL}=1.0 \times 10^{7} \mathrm{~cm} / \mathrm{sec}$ \\
$\mathrm{SPO}=1.0 \times 10^{7} \mathrm{~cm} / \mathrm{sec}$ & $\mathrm{SPL}=1.0 \times 10^{7} \mathrm{~cm} / \mathrm{sec}$ \\
$\mathrm{RF}=0.10$ & $\mathrm{RB}=0.90$ \\
\hline
\end{tabular}

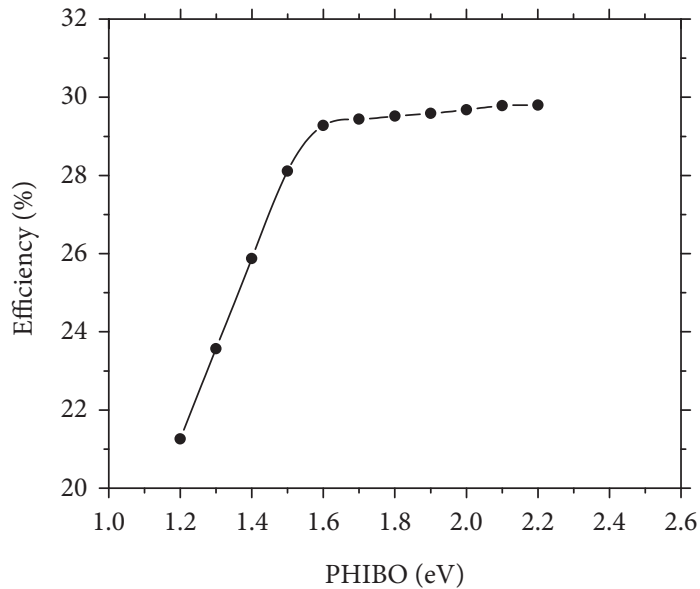

FIgURE 2: PHIBO versus efficiency plot of the proposed solar cell's front contact.

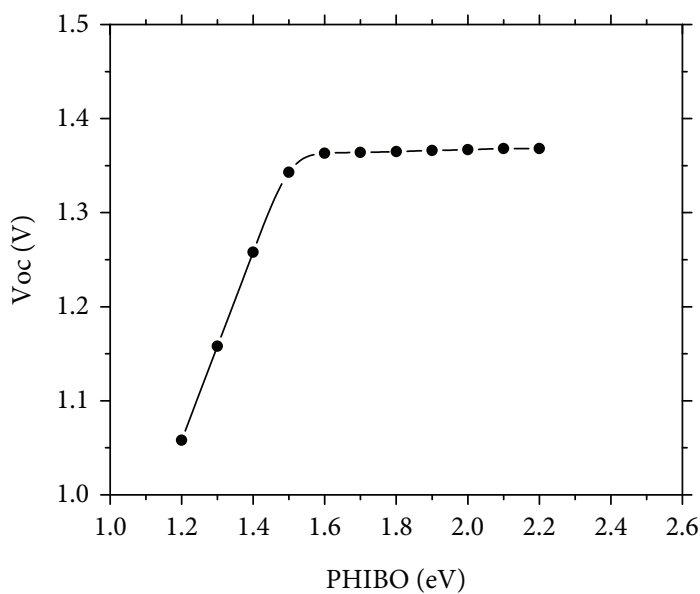

FIGURe 3: PHIBO versus Voc plot of the proposed solar cell's front contact.

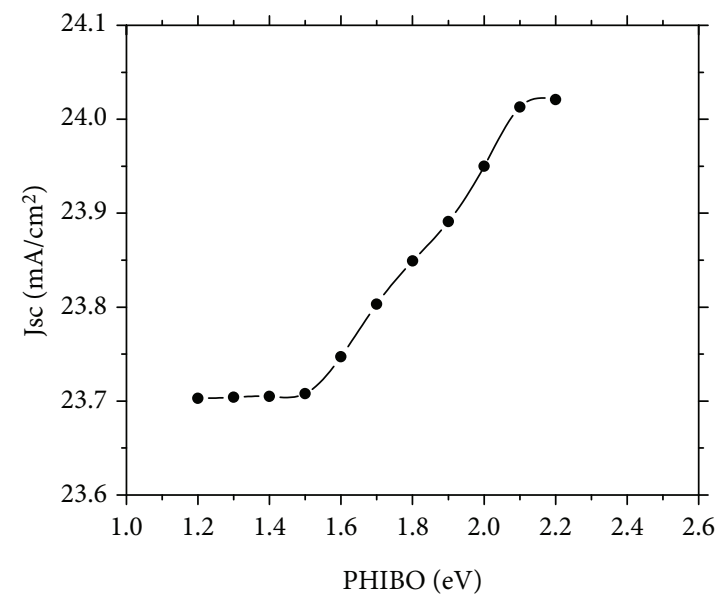

Figure 4: PHIBO versus Jsc plot of the proposed solar cell's front contact.

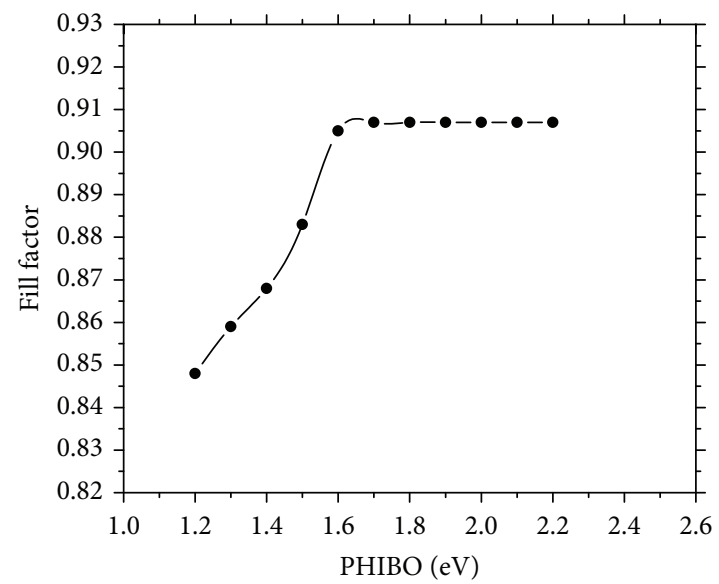

FIgURE 5: PHIBO versus fill factor plot of the proposed solar cell's front contact. 


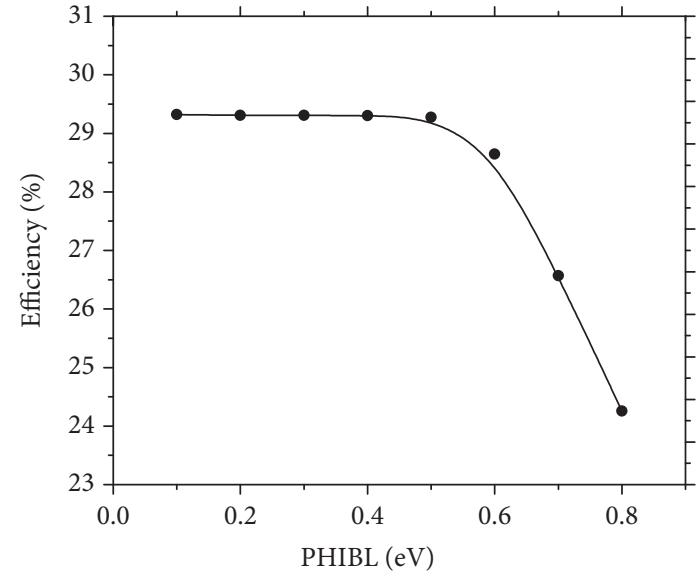

Figure 6: PHIBL versus efficiency plot of the proposed solar cell's back contact.

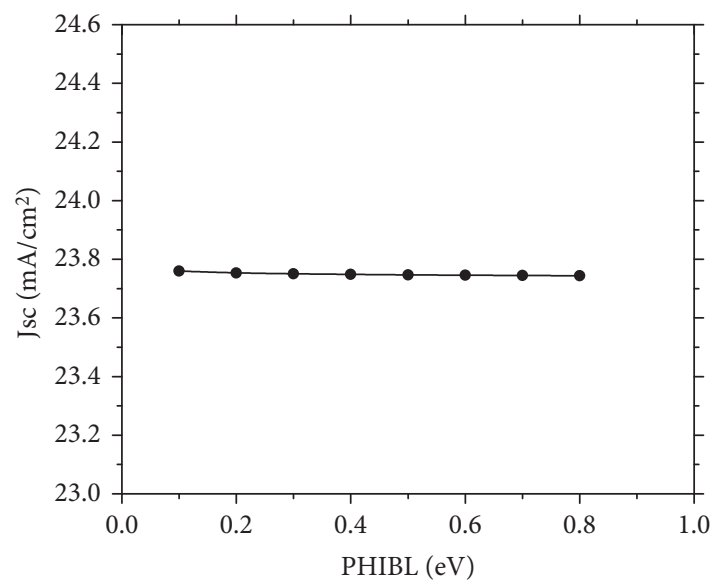

Figure 7: PHIBL versus Jsc plot of the proposed solar cell's back contact.

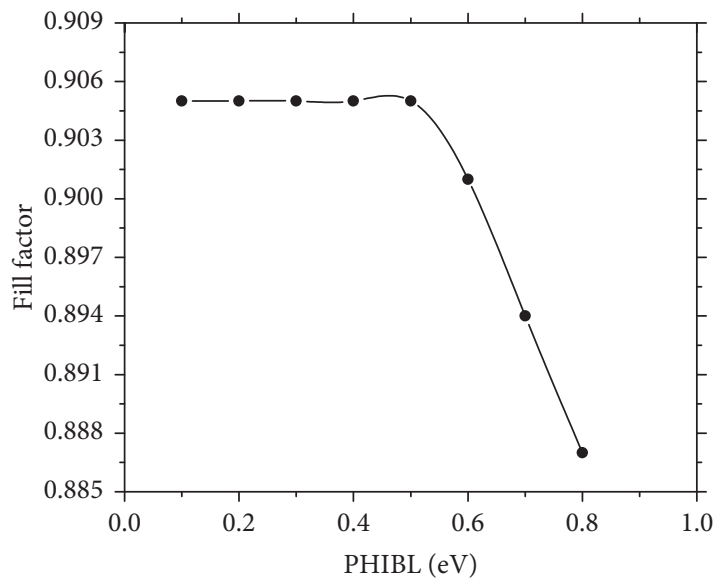

FIGURE 8: PHIBL versus fill factor plot of the proposed solar cell's back contact.

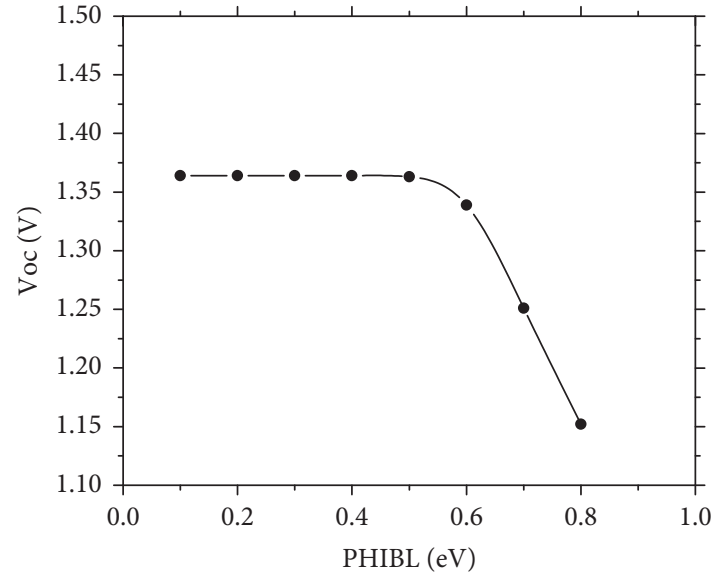

FIgUre 9: PHIBL versus Voc plot of the proposed solar cell's back contact.

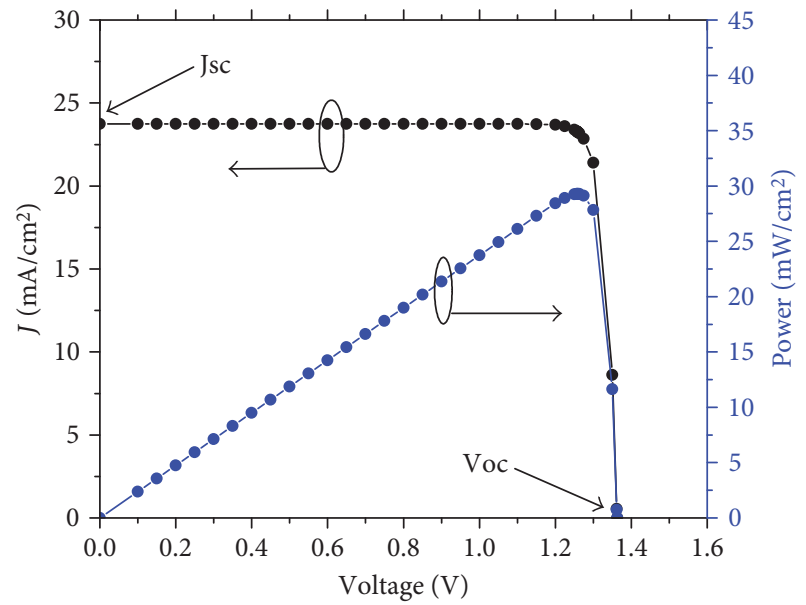

FIgURe 10: $J-V$ and $P-V$ plots of the proposed solar cell.

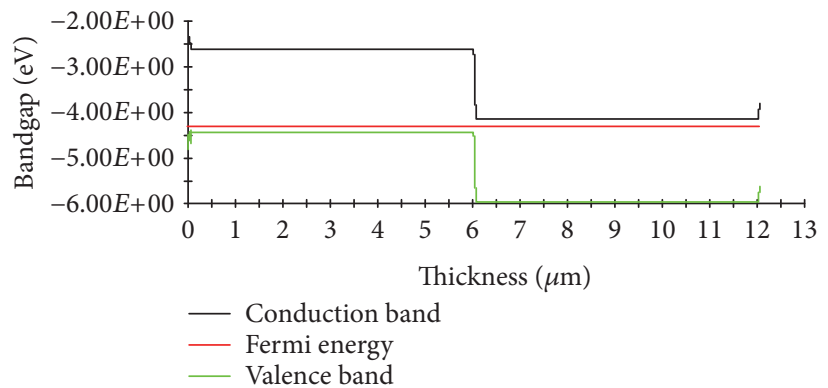

Figure 11: Band diagram of the proposed solar cell. 


\section{Conflicts of Interest}

The authors declare that they have no conflicts of interest.

\section{Acknowledgments}

The authors would like to thank the Pennsylvania State University, USA, for providing them the analysis of microelectronic and photonic structures one-dimensional (AMPS-1D) device simulation package.

\section{References}

[1] M. F. Ali and M. F. Hossain, "Effect of bandgap of EBL on efficiency of the p-n homojunction Si solar cell from numerical analysis," International Conference on Electrical \& Electronic Engineering (ICEEE), IEEE Explored, pp. 245-248, 2015, http://ieeexplore.ieee.org/document/7428268/.

[2] M. F. Ali and M. F. Hossain, "Simulation and observation of efficiency of p-n homojunction Si solar cell with defects and EBL by using AMPS-1D," International Journal of Engineering and Applied Sciences (IJEAS), vol. 2, no. 12, pp. 137-140, 2015.

[3] M. F. Ali, R. Islam, N. Afrin, M. Firoj Ali, S. C. Motonta, and M. F. Hossain, "A new technique to produce electricity using solar cell in aspect of Bangladesh: dye-sensitized solar cell (DSSC) and it's prospect," American Journal of Engineering Research, vol. 3, pp. 35-40, 2014.

[4] J. A. Turner, "A realizable renewable energy future," Science, vol. 285, no. 5428, pp. 687-689, 1999.

[5] M. F. Ali and M. F. Hossain, "Improving efficiency of an amorphous silicon (pa-SiC: H/ia-Si: H/na-Si: H) solar cell by affecting bandgap and thickness from numerical analysis," International Journal of Engineering and Applied Sciences (IJEAS), vol. 2, no. 12, 2015.

[6] May 2016, http://berc.berkeley.edu/why-are-solar-cells-madeof-silicon_1/.

[7] M. I. Kabir, S. A. Shahahmadi, V. Lim, S. Zaidi, K. Sopian, and N. Amin, "Amorphous silicon single-junction thin-film solar cell exceeding 10\% efficiency by design optimization," International Journal of Photoenergy, vol. 2012, Article ID 460919, p. 7, 2012.

[8] F. T. Zohora, M. A. M. Bhuiyan, and S. Saimoom, "Simulation and optimization of high performance CIGS solar cells," International Conference on Mechanical Engineering and Renewable Energy, 2015.

[9] D. Rached and R. Mostefaoui, "Influence of the front contact barrier height on the indium tin oxide/hydrogenated p-doped amorphous silicon heterojunction solar cells," Thin Solid Films, vol. 516, no. 15, pp. 5087-5092, 2008.

[10] K. Robert, C. C. Battaile, A. C. Marshall, D. B. King, and D. R. Jennison, Low Work Function Material Development for the Microminiature Thermionic Converter, Sandia National Laboratories, 2004, http://prod.sandia.gov/techlib/access-control. cgi/2004/040555.pdf.

[11] M. A. Hossain, J. Mondal, M. Feroz Ali, and M. A. A. Humayun, "Design of high efficient InN quantum dot based solar cell," International Journal of Scientific Engineering and Technology, vol. 3, no. 4, pp. 346-349, 2014.

[12] J. Arch, S. V. FonAsh, J. Cuiffi et al., A Manual for AMPS-1D for Windows 95/NT: A One-Dimensional Device Simulation,
Program for the Analysis of Microelectronic and Photonic Structures, and Pennsylvania State University 1997, USA.

[13] S. Banik and M. S. K. Shekh, Design and Simulation of UltraThin CdS-CdTe Thin-Film Solar Cell, East West University, 2014, http://dspace.ewubd.edu/bitstream/handle/123456789/ 1308/Sowrabh_Banik.pdf?sequence=1.

[14] May 2016, https://en.wikipedia.org/wiki/Air_mass_\%28solar_ energy\% 29. 

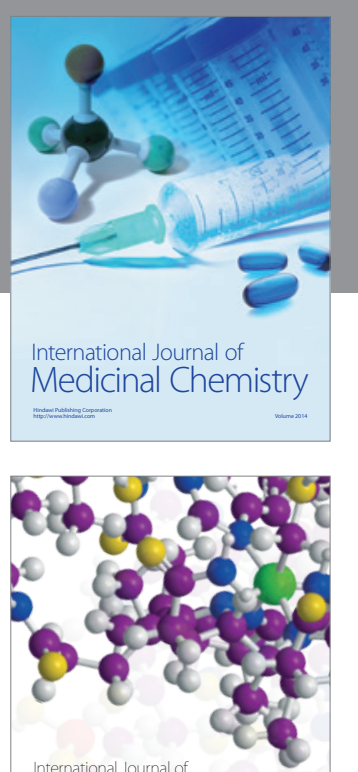

Carbohydrate Chemistry

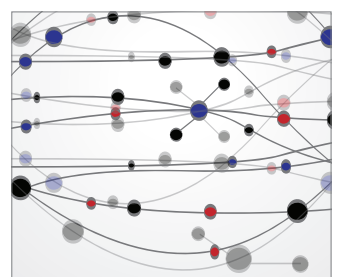

The Scientific World Journal
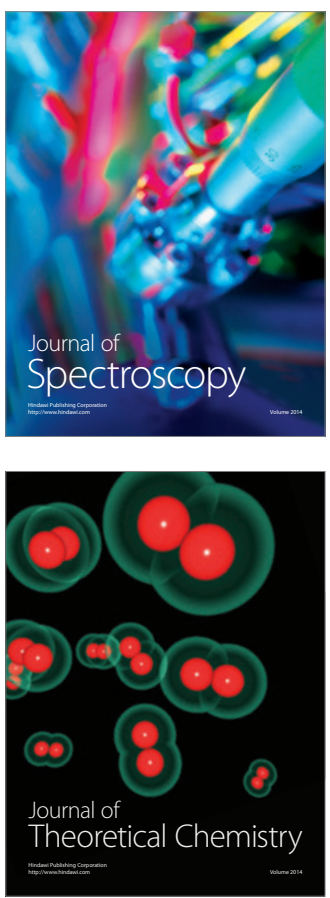
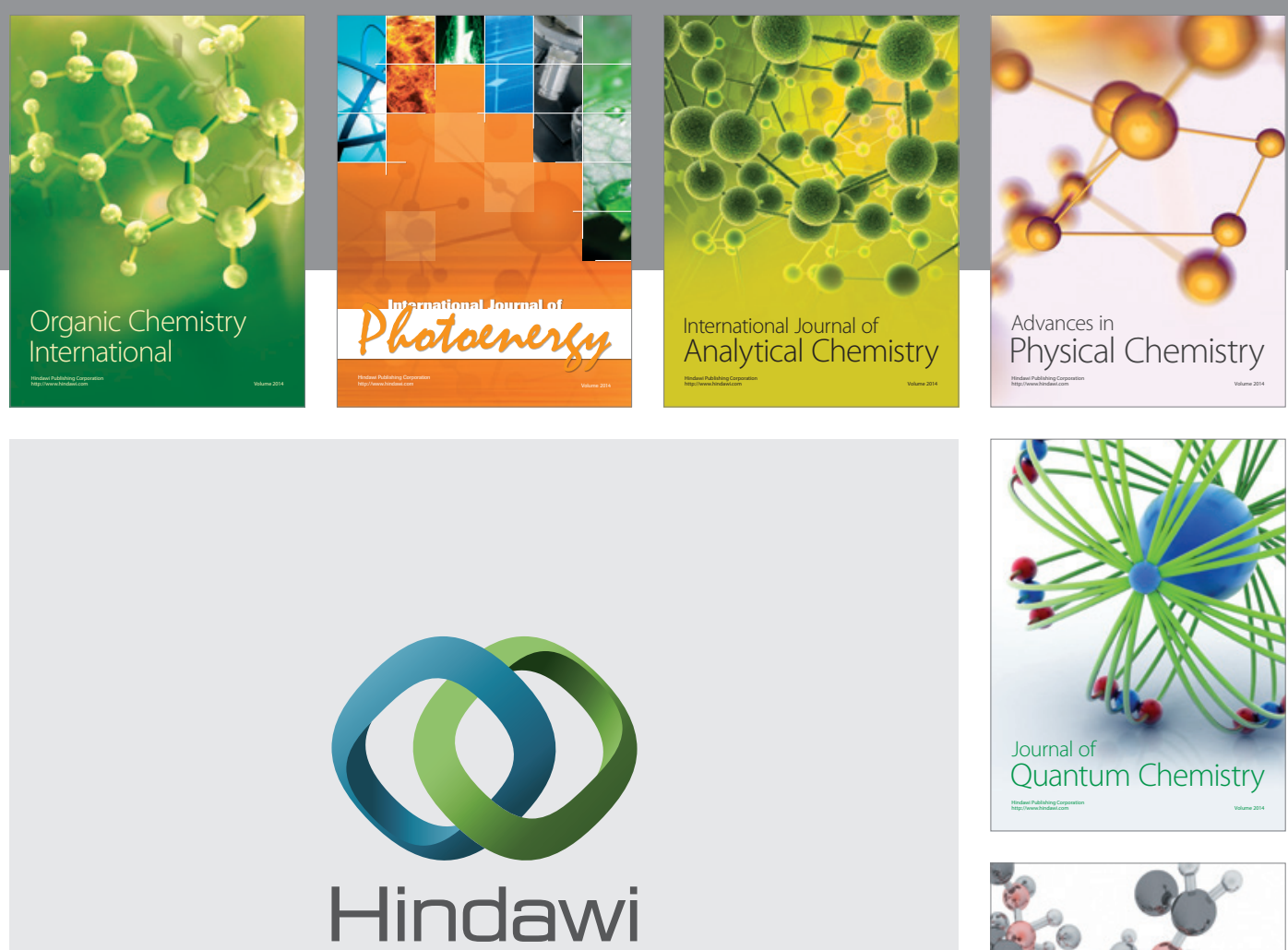

Submit your manuscripts at

https://www.hindawi.com

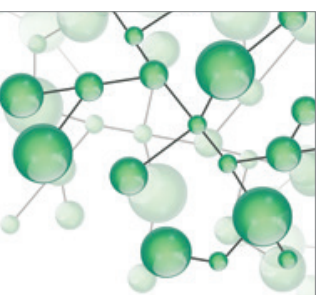

International Journal of

Inorganic Chemistry
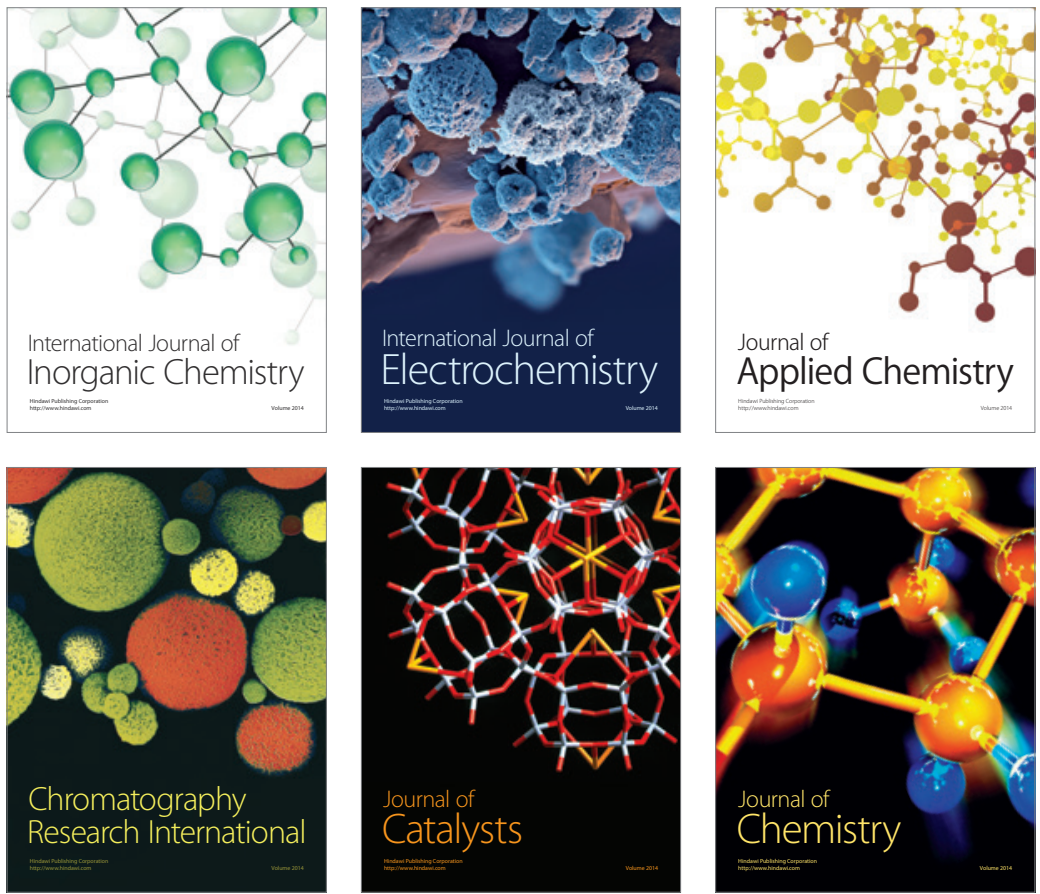

Journal of

Applied Chemistry
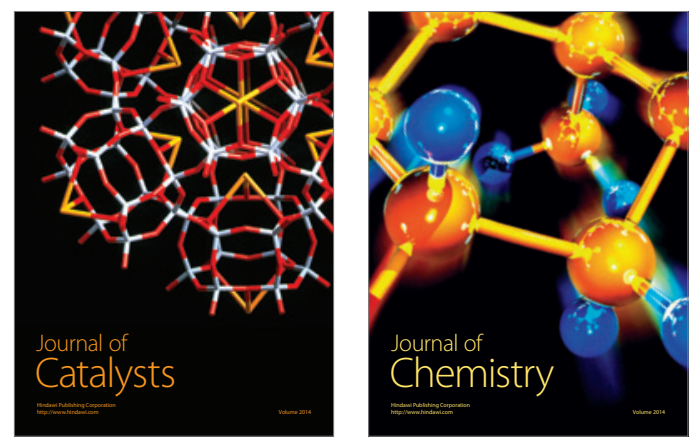
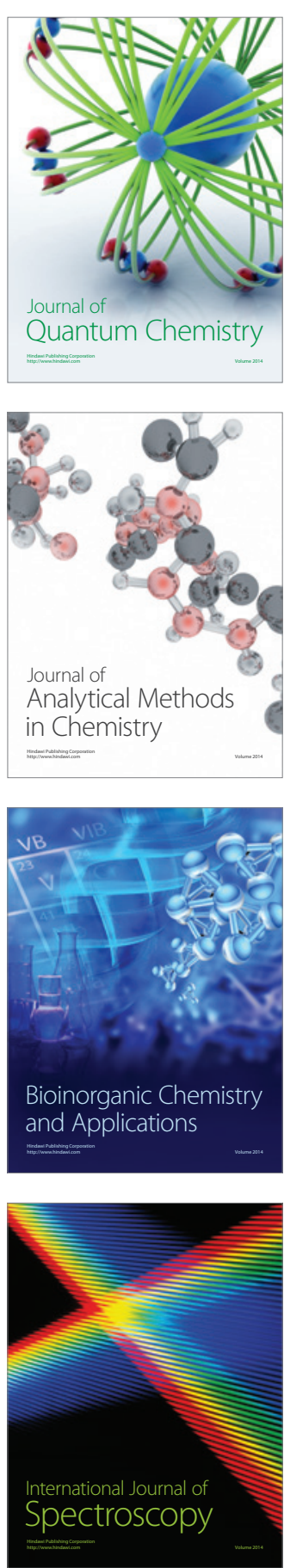